\title{
Effect of Artificial Inhomogeneity of Density and Drilling on Dynamic Properties Developed by Poplar Block Species (Populus nigra) Jointed with Oak Wood (Quercus castaneifolia) Beams
}

\author{
Mostafa Kohantorabi, ${ }^{a}$ Amirhooman Hemmasi, ${ }^{\text {b, } *}$ Mohammad Talaeipour, ${ }^{\mathrm{c}}$ \\ Mehran Roohnia, ${ }^{\mathrm{d}}$ and Behzad Bazyar ${ }^{\mathrm{e}}$ \\ Inhomogeneities in wood and wood products are evident. Sometimes \\ these inhomogeneities are combined with other inhomogeneities such as \\ drilling. Each can have different effects on dynamic properties, and these \\ footprints can cause hidden defects in wood and wood products. In this \\ research, the effects of artificial inhomogeneity of density and drilling \\ diameters $(1 \mathrm{~mm}, 3 \mathrm{~mm}, 5 \mathrm{~mm}$, and $10 \mathrm{~mm})$ on dynamic properties of the \\ beams produced from oak wood jointed with poplar blocks (one at the end \\ and the other at the central part of the beam) were investigated. Free \\ vibration on a free-free beam test was subjected for the evaluations. The \\ results indicated that factors such as dynamic modulus of elasticity, \\ acoustic coefficients, and damping capacity, were affected by both \\ inhomogeneity and drillings. The acoustical converting efficiency showed \\ the exact location of inhomogeneity. It also showed the level of drilling \\ diameter.
}

Keywords: Acoustical converting efficiency; Defect; Drilling; Inhomogeneity; Oak wood; Vibration

Contact information: a: Ph.D. Student, Department of Wood and Paper Engineering, Faculty of Natural Resources and Environment, Science and Research Branch, Islamic Azad University, Tehran, Iran, P.O. Box 14515/775; b: Department of Wood and Paper Engineering, Faculty of Natural Resources and Environment, Science and Research Branch, Islamic Azad University, Tehran, Iran; P.O. Box 14515/775; c: Department of Wood and Paper Engineering, Faculty of Natural Resources and Environment, Science and Research Branch, Islamic Azad University, Tehran, Iran. P.O. Box 14515/775; d: Department of Wood and Paper Science and Technology, Faculty of Agriculture and Natural Resources, Karaj Branch, Islamic Azad University, Karaj, Iran. P.O. Box 31485/313; e: Department of Wood and Paper Engineering,

Faculty of Natural Resources and Environment, Science and Research Branch, Islamic Azad University, Tehran,Iran, P.O. Box 14515/775; *Corresponding author: h_hemmasi@srbiau.ac.ir

\section{INTRODUCTION}

Wood is a material with joinability - it is capable of being drilled in different locations with other wood species of different densities. Density changes and drilling due to the jointing in the primary wood in each location with different species will have different effects on its acoustic properties.

Non-destructive tests (NDTs) are of considerable importance in the wood industry due to their capability in assessing and predicting the mechanical properties of wooden materials (Hu et al. 2005; Wang et al. 2008). These tests are widely run in classifying wood species and the products thereof. In the wood industry, the following are obtained through NDTs: the bending strength of as-built oriented strandboard (OSB), the dynamic modulus 
of elasticity in joints, the quality of woods impregnated with Creosote, the plywood strength, and the wood joints, existing inhomogeneities therein, and wood products thereof (Kubojima et al. 2005; Nzokou et al. 2006; Roohnia et al. 2012).

Assessing the wood resources and wood products in as-built structures and considering their maintenance cost is a major issue. Among these NDTs, the free flexural vibration in a free-free beam is of specific importance because of its ease of use and costeffectiveness (Bodig and Jayne 1993; Bucur 2006). One of the applications of this test is to discover different types of inhomogeneity and defects in wooden beams. Ouis (2004) assessed the effects of cracks in wooden rods and the possibility of identifying and locating them. During his research, it became clear that the presence of cracks led to a decrease in the number of natural frequencies. A direct relation between the level and number of defects and the values of the damping capacity was found, but a cracked area was not discoverable based on the studied parameters. Kubojima et al. (2005) applied the forced vibration in the free-free beam method to assess the effect of making artificial inhomogeneity by metal bands on Sitka spruce wood (Picea sitchensis) through the third vibration mode. The results revealed that without using metal band joints, the frequency of the first mode increases compared to the state where the metal band joint is applied. A significant correlation was noticed when comparing the jointed beams with and without metal bands based on Timoshenko beam theory, but still the inhomogeneous position could not be discovered. Yang et al. (2008) found the vibrations of homogeneous and inhomogeneous beams based on Euler-Bernoulli theory in both the free and forced vibration states. These beams were identified by cracks on the surface. They observed that the natural frequencies decreased because of defects and because of the dynamic bending changes (due to the existence of cracks). Beams with less modes have lower frequencies and exhibited more dynamic bending. They could not pinpoint a damaged area. Roohnia et al. (2011) assessed the effect of drilling different areas of clear beech wood (Fagus orientalis) on the resulting frequency from longitudinal vibration of the samples. They found that the first mode frequency of the longitudinal vibration is influenced by the location of the hole in sound wooden beams and the resulting frequency decreases or remains unchangeable in relation to the location of the hole. Through applying the longitudinal vibration method, they found a hole in the first sound beam that was tested. Kubojima et al. (2014) applied the longitudinal vibration method to assess the effect of making artificial inhomogeneity using rectangular metal bands as the antinode simulations in Sitka spruce (Picea sitchensis). The samples obtained before and after applying metal band joints underwent the longitudinal vibration test in different locations. The results indicated that except for the effect of mass addition in the initial sections of the beam, in other parts, the process of adding mass has a significant effect on the obtained modulus of elasticity, but they could not discover the effect of artificial inhomogeneity location on dynamic modulus of elasticity. Kohantorabi et al. (2015) assessed the effect of moisture and temperature variations in three wood drying programs and compared the obtained results with static tests. They concluded that the resulting variation in acoustical converting efficiency (ACE) is the most appropriate criterion in assessing the efficiency of wood drying programs adopted for this type of beam and identified the resulting inhomogeneities, like the cracks during the wood drying process. They did not discover any developed inhomogeneous location during wood drying processes. 
Wood, due to its unique properties, is of great importance for its application in engineered structures and often has the capability of being joined to different species because its fibrous structure. These properties not only prevent wasting this valuable material, but also express its appropriate use in timber structures (Ayarkwa et al. 2001).

To join wood with other different materials for the association of stresses in the wood or the structure with the joint, it is necessary to investigate its place and effect on the mechanical properties of the joints. The objective of this study was to test the small pieces (replaced and jointed with simple end-to-end joints) of poplar wood (Populus nigra) in the main beam of oak wood (Quercus castaneifolia) in two areas (the end of the beam and central part of the beam without any length variation in the major beam). Four 1-, 3-, 5-, and 10-mm diameter holes were drilled on the inserted blocks of poplar wood in oak wood to determine: 1) joint place, 2) the effect of density decrease, and 3) the dynamic effect of each drilling stage on the dynamic properties of joined beams and free flexural vibration in the free-free beam.

\section{EXPERIMENTAL}

\section{Materials}

The test specimens constituted of selected oak wood (Quercus castaneifolia) lumber pieces (Iran Tejarat, Rasht, Iran) that served as a basic and high-density wooden beam. The large-sized lumber pieces were carefully reduced to 50 small rectangular pieces with dimensions of $2 \mathrm{~cm} \times 4 \mathrm{~cm} \times 72 \mathrm{~cm}$ (Radial $\times$ Tangential $\times$ Longitudinal). Thirty pieces were visually selected from clear specimens on a random basis in accordance with ISO 3129 (1975) qualifications. The samples were conditioned at $65 \pm 5 \%$ relative humidity (RH) and $20 \pm 2{ }^{\circ} \mathrm{C}$ to establish an equilibrium moisture content of $12 \%$. The specimens were exposed to free bending vibration of the free-free beam test, with respect to three initial vibration modes, and the trends of Timoshenko bending theory with the highest correlation coefficients were applied to accept and select identical specimens prior to further experiments. The selection procedure was in accordance with that of Brancheriau et al. (2010) and Roohnia et al. (2011, 2012). As shown in Fig. 1, Timoshenko's bending theory (1921) was adopted initially for isotropic materials to determine the clearest specimens. It benefits from a linear trend fitted to three or more points calculated from three or more consecutive modal frequencies.

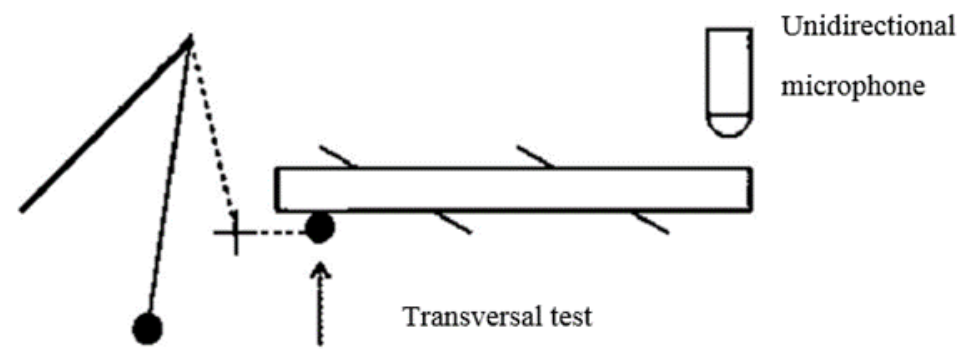

Fig. 1. Schematic view of free flexural vibration in free-free beam test (the beams are placed at antinode close to the blocking on the support) (Image suggested by Brancheriau et al. 2010) 
If a sample loses its homogeneity, the correlation coefficient of the fitted trend would decrease to a lower value; based on previous publications (Bordonné 1989; Brancheriau et al. 2010; Roohnia et al. 2012; Roohnia and Kohantorabi 2015), the coefficients of determination from Timoshenko's beam theory, equal to or higher than 0.99 was accepted. Finally, the total of accepted specimens was decreased to 10. These evaluations were made using NDTlab® Software (Islamic Azad University-Karaj Branch, v.2.03, Karaj, Iran) (Roohnia 2007).

\section{Methods}

After the selection of the sound specimens, any new trace with either positive or negative impact was attributed to the perfectness of the joints. Completely clear samples of poplar wood of nominal dimensions $2 \mathrm{~cm} \times 4 \mathrm{~cm} \times 4 \mathrm{~cm}$ (Radial $\times$ Tangential $\times$ Longitudinal) were supplied and transported to the mentioned environment as the heterogeneous wood in the oak beams. In all stages of the test (from oak wood without any joint to oak wood joined to poplar wood with the $10 \mathrm{~mm}$ diameter hole), the acoustic and physical properties of the beams, including density, dimensions, $\mathrm{RH}$, frequency, and the other factors, were measured, and all test stages were run in the climatic chamber with the balanced moisture at $12 \%$. After three weeks, the primary and clear samples of oak wood become exposed to free bending vibration in the free-free beam to record the primary acoustic properties. The qualified samples for the test (10 samples) were divided into two groups of five samples each. From the first group, blocks with wood of $2 \mathrm{~cm} \times 4 \mathrm{~cm} \times 4$ $\mathrm{cm}($ Radial $\times$ Tangential $\times$ Longitudinal) dimensions from the end of part of the beam and from the second group, the same from the central part were cut out by jigsaw (to impose the smallest effect on samples) and immediately joined together by polyvinyl acetate (Chasb Chob Shomal, Tehran, Iran). Until completely joined, they were held inside the handhold (hand vise) and then transferred to the climatic chamber (in each stage of blocking during the research, a handhold was used to make the appropriate joint). After three weeks, the jointed oak-oak samples were exposed to free flexural vibration in the free-free beam test to assess the effect of the blocking on the acoustic properties of the beams. After this stage, the oak wood blocks were taken out from inside the beams by a jigsaw. After cleaning the glue line of the samples by using emery paper, the poplar wood blocks were replaced in the end and center of the oak woods in both groups.

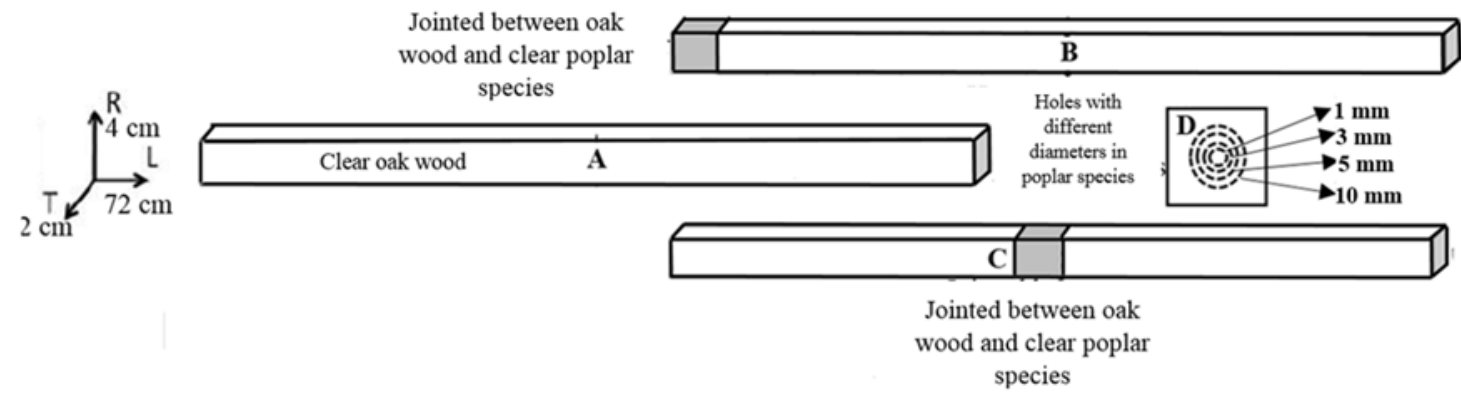

Fig. 2. Schematic view of the clear oak wood and the conjunction points with poplar block wood in two groups and the four stage drilling to make artificial inhomogeneity in density in oak beams (A: Clear wood, B: joint in end of beams, C: joint in central part of beams, D: surface schematic view of four stages of drilling in artificial inhomogeneity on density by poplar block wood in oak wood beams) 
After these stages of making the appropriate joints, the oak-poplar blocking wood in the end and central of the oak wood were exposed to free flexural vibration in the freefree beam test to assess the effect of the blocking of the poplar wood on the acoustic properties of the oak beams. Then, the samples of each group were drilled to make holes of four diameters $(1 \mathrm{~mm}, 3 \mathrm{~mm}, 5 \mathrm{~mm}$, and $10 \mathrm{~mm})$. At every drilling stage, after ensuring that the aforementioned stages were observed, the tests were run on the samples (Fig. 2).

After obtaining the $\mathrm{n}^{\text {th }}$ eigenfrequency through fast Fourier transform (FFT), based on coordinates of evaluated spots from at least three initial modes of vibration, Young's modulus' specific flexural modulus was determined. It was determined through a linear regression as shown in Eq. 1,

$$
a_{\mathrm{n}}=\left(\frac{E}{\rho}\right)-\left(\frac{E}{K \times G_{\mathrm{ij}}}\right) b_{\mathrm{n}} \quad \mathrm{R}^{2} \geq 0.99
$$

where the intercept $(E / \rho)$ is the flexural specific dynamic Young's modulus $\left(\mathrm{Pa}^{\mathrm{m}} \mathrm{m}^{3} / \mathrm{Kg}\right.$ or $\left.\mathrm{m}^{2} / \mathrm{s}^{2}\right), G_{\mathrm{ij}}$ is the shear modulus (Pa) in LR or LT plane (not applied in this approach), $K$ is the shape coefficient, equivalent to 0.833 (Brancheriau and Baillères 2002), $a_{\mathrm{n}}$ and $b_{\mathrm{n}}$ are the coordinates of the evaluated spots from at least three initial modes of flexural vibration, $n$ is the mode number, and $\mathrm{R}$ is the correlation coefficient of the Timoshenko's linear trend. The origin and background to the derivation of the Eq. 1 is presented in detail in literature (Roohnia et al. 2010). The NDT-lab ${ }^{\circledR}$ Portable System Setup (Roohnia 2007), (Islamic Azad University-Karaj Branch, v.2.03, Karaj, Iran) was used for the flexural free vibration test (Fig. 1).

Damping of vibration was introduced as shown in Fig. 3, and was calculated using Eqs. 2 and 3 (Roohnia 2019):

$$
\begin{aligned}
& \lambda=\frac{1}{n} \ln \left|\frac{X_{1}}{X_{\mathrm{n}+1}}\right| \\
& \tan \delta=\frac{\lambda}{\pi}
\end{aligned}
$$

where $\lambda$ is the logarithmic decrement, and tan $\delta$ corresponds to the damping of vibration.

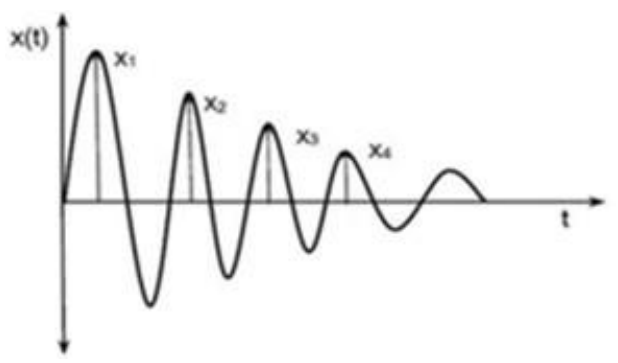

Fig. 3. Expressions of damping capacity in the temporal field through logarithmic decrement $\lambda$

The acoustical coefficient $(K)$ and acoustical conversion efficiency $(A C E)$, based on modulus of elasticity, density, and damping factor, are applied in the musical instrument industry as criteria for selecting the proper wood (Ono and Norimoto 1983; Tsoumis 1991; Roohnia 2019). These parameters are calculated through Eqs. 4 and 5,

$$
K=\frac{E}{\rho^{3}}
$$




$$
A C E=\frac{K}{\tan \delta}
$$

where $K$ is the acoustic coefficient $\left(\mathrm{m}^{4} \cdot \mathrm{s}^{-1} \cdot \mathrm{kg}^{-1}\right), E$ is the modulus of elasticity $(P a), \rho$ is the density of wood specimens $\left(\mathrm{kg} \cdot \mathrm{m}^{-3}\right)$, and $A C E$ is the acoustical converting efficiency $\left(\mathrm{m}^{4} \cdot \mathrm{s}^{-}\right.$ $\left.{ }^{1} . \mathrm{kg}^{-1}\right)$. The correlation among the obtained volumes from the dynamic properties of clear oak beams through replaced and drilled poplar wood beams with $10-\mathrm{mm}$ diameter holes in both inhomogeneity of density groups was assessed through the Pearson correlation test and the regression fit model. A comparison of each one of the mechanical properties obtained from each one of the test stages was also made by a statistical T-test at $95 \%$ confidence level. The SPSS v.11.5 software (IBM Corp., Armonk, NY, USA) was applied in the statistical tests and Microsoft Excel 2013 (Microsoft Corporation, Redmond, WA, USA) was applied to draw the regression line and the diagram. The comparison was based on the clear qualities of the wood.

\section{RESULTS AND DISCUSSION}

Variations of the dynamic modulus of elasticity values from the clear oak beam stage through the replacement of the poplar wood blocks (until the last stage of drilling) are shown in Figs. 4 and 5. The oak-oak joint at the end part of the beams did not have an effect on the dynamic modulus of elasticity values at $95 \%$ confidence level (Fig. 4).

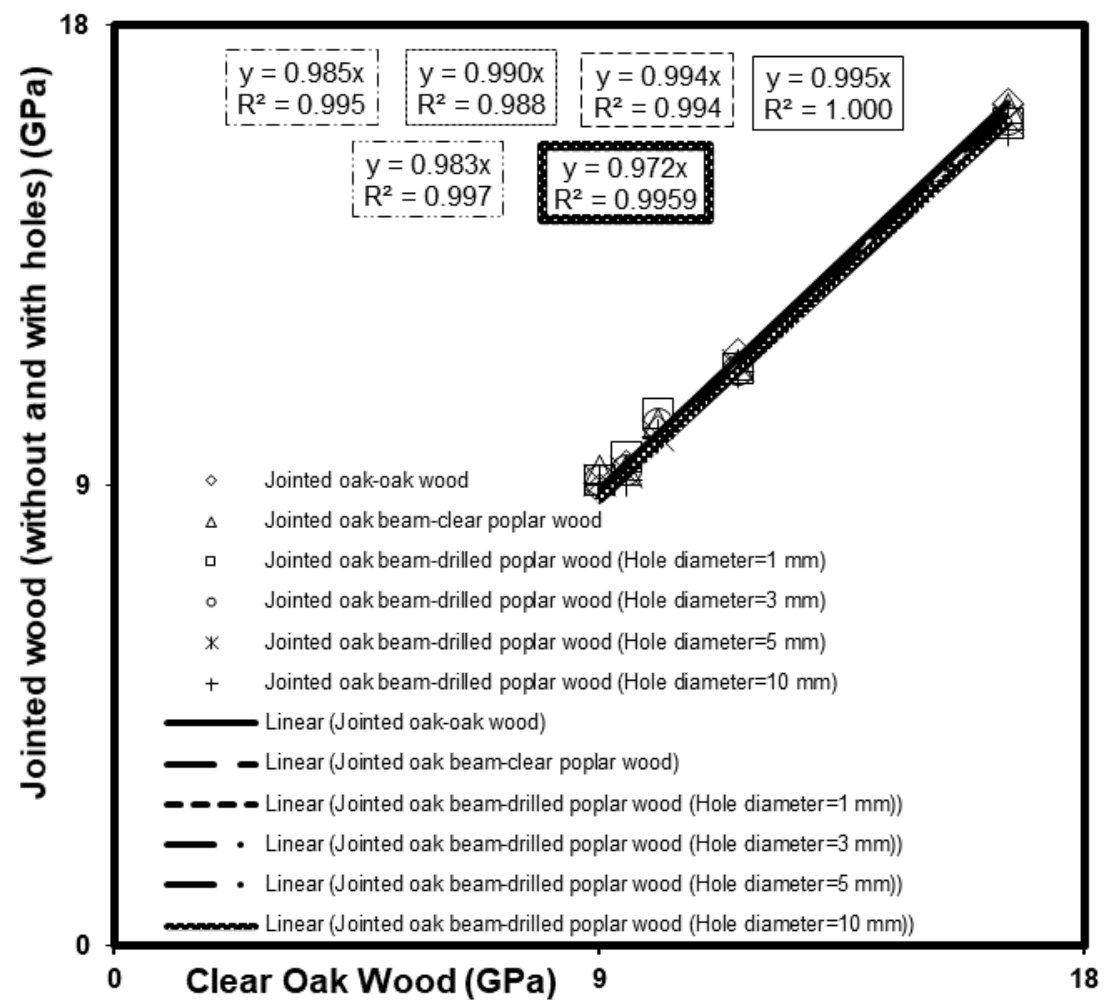

Fig. 4. Comparison of the dynamic modulus of elasticity values between clear oak wood and jointed oak wood and poplar block wood without hole before and after, for four drilling stages at one of the ends of the beam (see Fig. 2) 


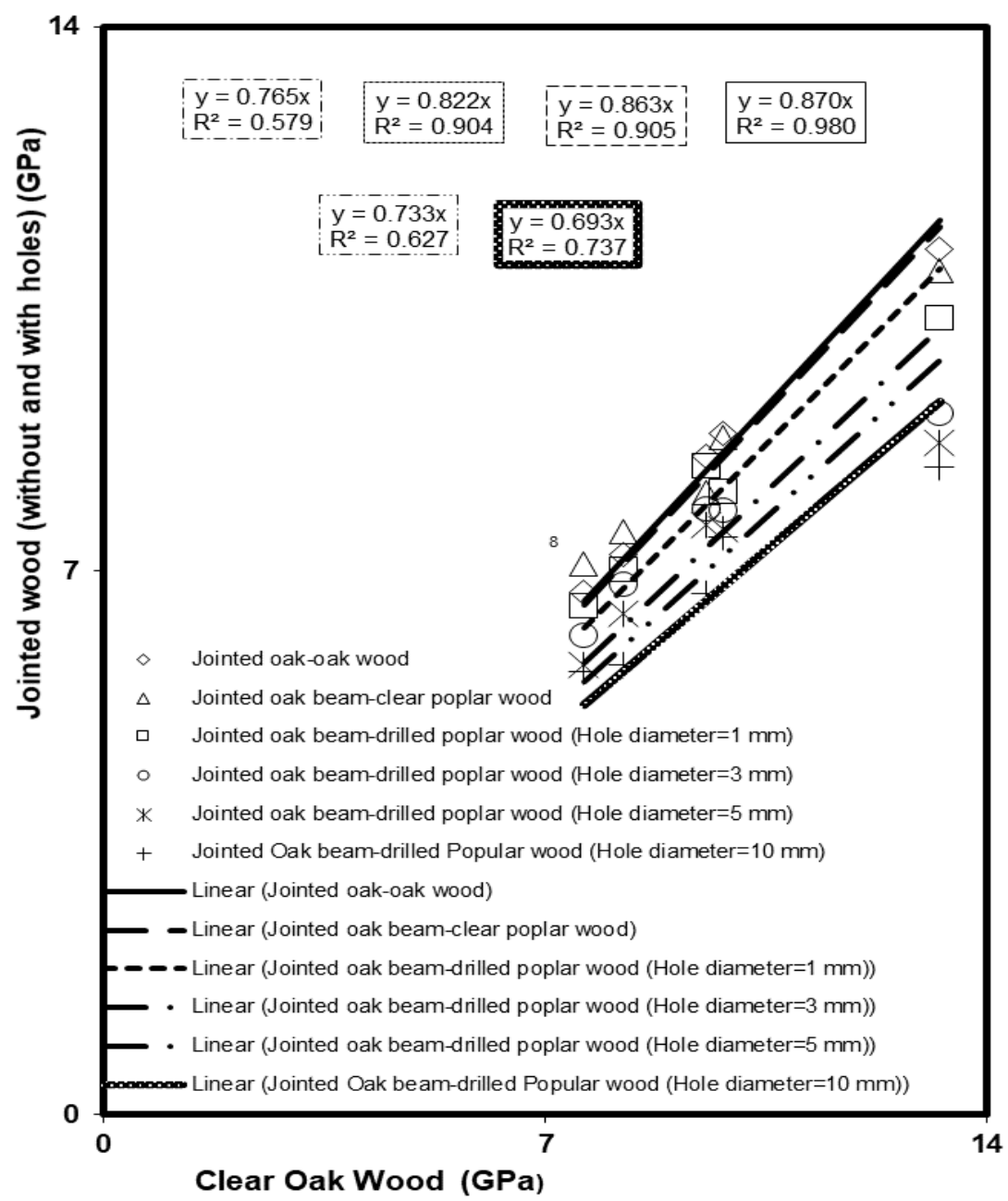

Fig. 5. Comparison of the dynamic modulus of elasticity values between clear oak wood and jointed oak wood and poplar block wood without hole before and after, for four drilling stages at the central of the beam (see Fig. 2)

Even the replacement of the poplar wood did not have any dynamic response regarding the values of dynamic modulus of elasticity. Only when applying the $10-\mathrm{mm}$ diameter bit size at the drilling stage did a different mechanical response in the oak-poplar joint beams become visible at $95 \%$ confidence level. The joint in the central part of the beam (Fig. 5) of the same oak joint did have an effect on the dynamic modulus of elasticity and in the next stages (replacement of the poplar wood blocks and the drilling holes of 1 $\mathrm{mm}, 3 \mathrm{~mm}, 5 \mathrm{~mm}$, and $10 \mathrm{~mm}$ diameter led to decrease in the values of dynamic modulus of elasticity compared to the sound oak wood) at $95 \%$ confidence level. The variations of dynamic modulus of elasticity in the central part of the beam was an essential factor for assessing the level of inhomogeneity.

The frequency obtained from the vibration of one material depends on different factors, including dimension, moisture, density, and the location of the inhomogeneity occurrence in inhomogeneous beams (Harris and Piersol 2002). The density changes at the most cases were about $2 \%$ of the total density of the beams. This low value was attributed 
to the controlled conditions in the climatic chamber such as humidity and temperature and the insignificant effect on the density at $95 \%$ confidence level, and also the absence of variations in length of the beams from the beginning level of the tests to the end of the tests. So according to Fig. 6, the only variant factor was the location of inhomogeneity in the two joint groups. The joint location in the beams, the inhomogeneity location in the end of part the beams, was out of the range of the first mode of free flexural vibration in freefree beam. The joint place in the beams, the inhomogeneity location in the central part, was completely in the antinode of the first mode of free flexural vibration in free-free beam. This gave two different dynamic responses from two replacement locations in each phase of the test in joined oak beams. Making damaged joints in the central part of the beam in the available studies led to a decrease in the dynamic modulus of elasticity at $95 \%$ confidence level (Roohina et al. 2012).

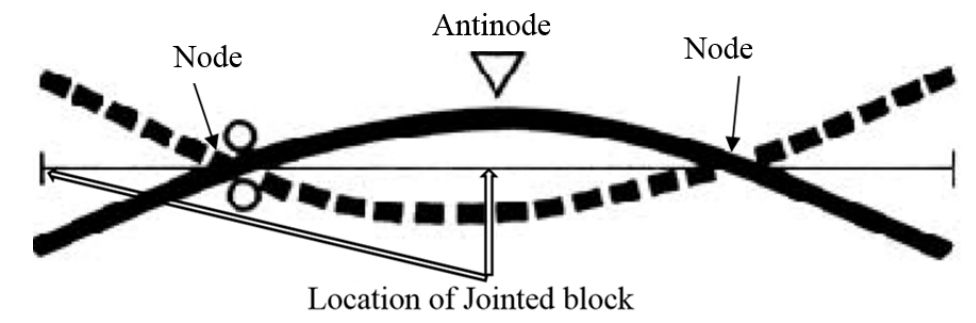

Fig. 6. Schematic of antinode and node in first mode of free flexural vibration in free-free beam

Acoustic coefficient values in the end and central parts of the beams are shown in in Figs. 7 and 8. Based on the obtained results for the modulus of elasticity and very partial variations in density, the results presented in Figs. 7 and 8 are predictable, with the exception that in this study, the decrease in special mass (even partial) was due to making a joint in the poplar wood species and drilling in different stages of the study. 


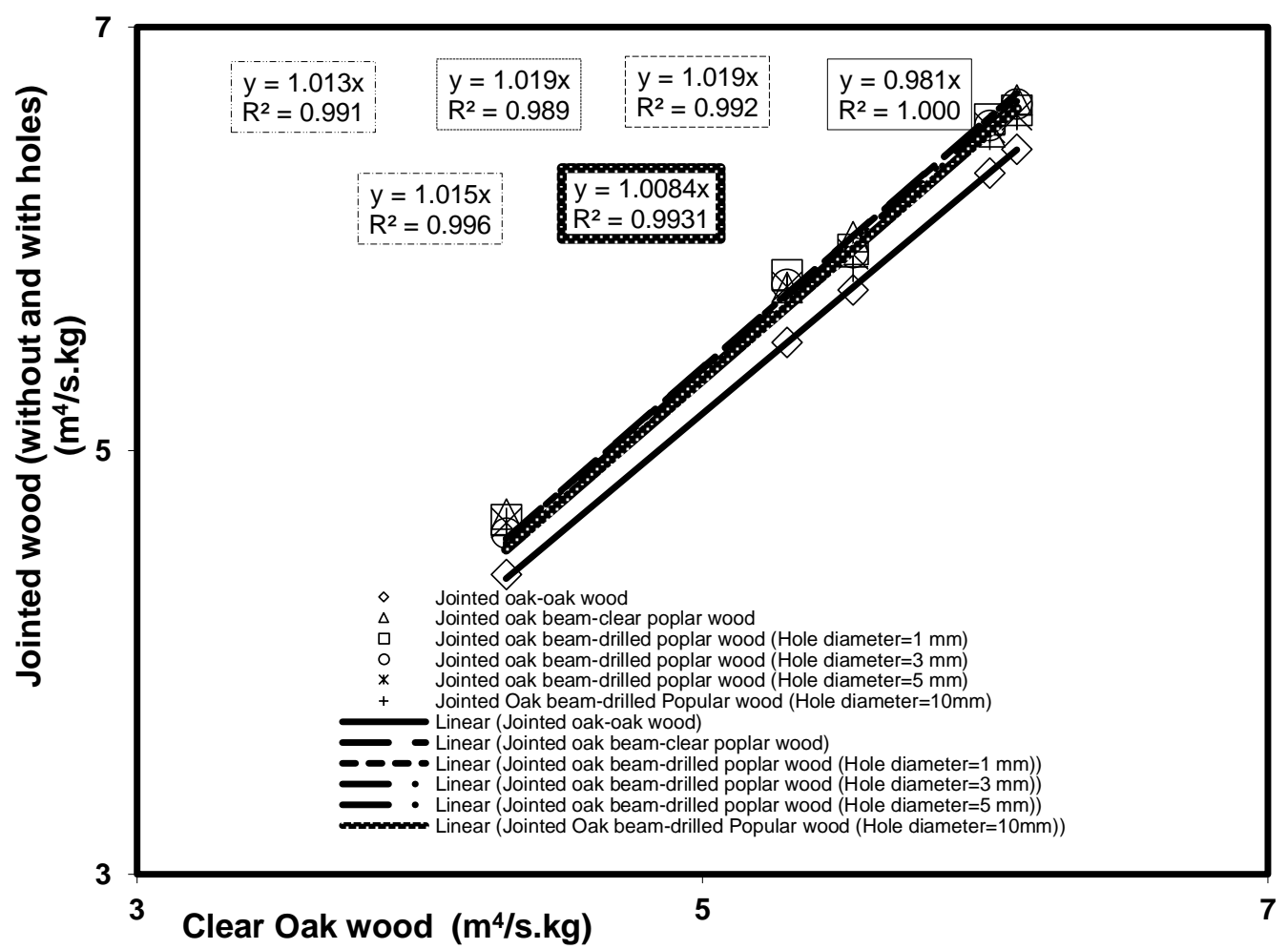

Fig. 7. Comparison of the acoustic coefficient values between clear oak wood and jointed oak wood and poplar block wood without hole before and after, for four drilling stages at one of the ends of the beam (see Fig. 2)

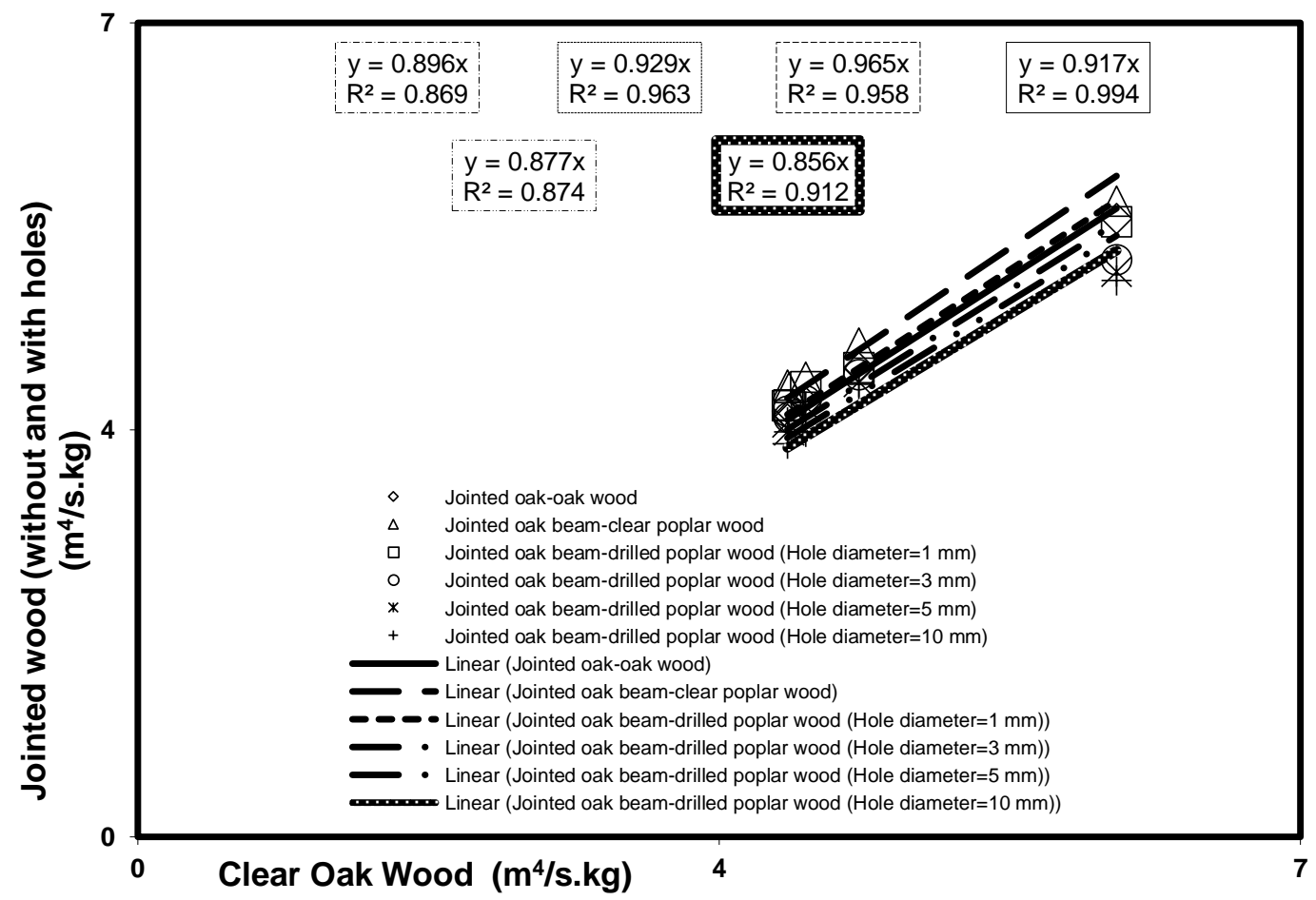

Fig. 8. Comparison of the acoustic coefficient values between clear oak wood and jointed oak wood and poplar block wood without hole before and after, for four drilling stages at the center of the beam (see Fig. 2) 
Based on the existing theory, in a clear wood sample, lower levels of special mass and higher dynamic modulus of elasticity correspond to a greater acoustic coefficient and enable vibration. The damping capacity takes more time (Tsoumis 1991). Imposed damage on the beam cannot be a considerable factor in assessing the quality of the beams in different stages of the test. The imposed damages cause a partial increase in the level of joined woods in the end part of the beam and the variation trend in the next stages is like that observed in the modulus of elasticity. An increase in this factor in joints in the central part of the beam and in different stages of the study, like the joint at the end of the beam (Figs. 7 and 8) has a similar trend with that of the dynamic modulus of elasticity, with the exception that this an increasing trend.

The damping capacity trends of the vibration in the different stages of the test are shown in Figs. 9 and 10, where the variations of this factor can be observed from the occurrence of the joint in the end part of the wood to the end of the drilling stages. Figures 9 and 10 show the values of this factor increased gradually from its natural stages to the end of the test stages. Such an increase is regular, and the related values increased with a mild gradient from the end of the clear oak beam to the end of the test stages. In the joint made at the end part of the beam, only one end of the replaced blocks was made sticky, while the joints on both sides of the replaced blocked in central part of the beams led to increases in the damping factor. This process led to less inhomogeneity compared to the blocks replaced in the central part of the beam.

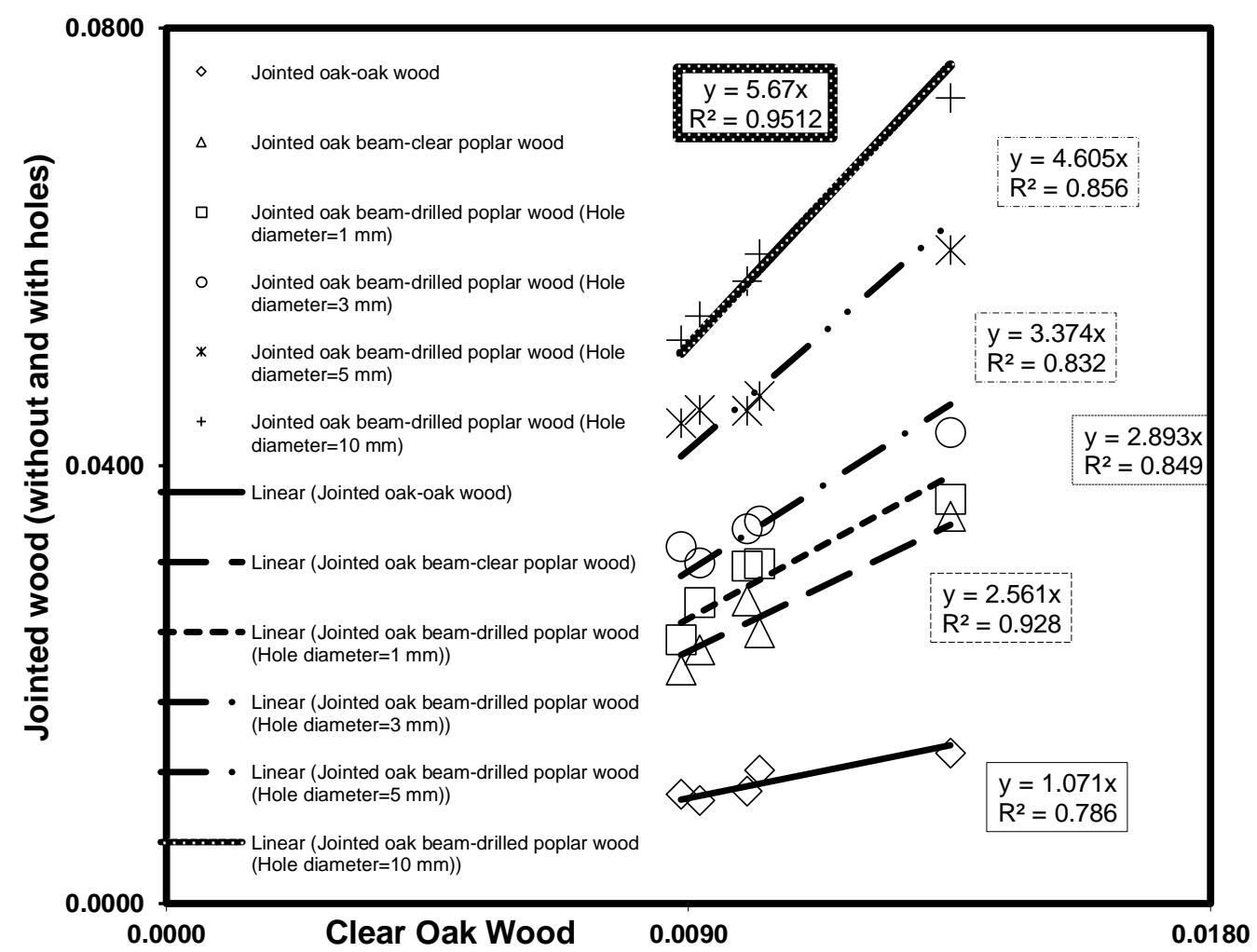

Fig. 9. Comparison of the damping capacity values between clear oak wood and jointed oak wood and poplar block wood without hole before and after, for four drilling stages at one of the ends of the beam (see Fig. 2) 
In the joined samples at the central part of the beam (Fig. 10), the intensity of damping capacity increased more than that of the joined samples at the end of the beams at $95 \%$ confidence level. The damping capacity was a dimensionless characteristic of wood, influenced by wood species, vibration direction, moisture, and other factors. The lower its values, the better its noise conductance therein (Tsoumis 1991). In the past, the values of this factor increased due to the presence of inhomogeneity (Wilcox 1978; Ouis 2004; Hu and Afzal 2006; Aramaki et al. 2007; Sedik et al. 2010; Roohina et al. 2011; Kohantorabi et al. 2015). In this research, the joined samples at the central part of the beams (Fig. 10) increased the intensity of damping capacity more than that of the joined samples at the end of the beam. In addition to the observation in Fig. 6 and the contribution of the location of the inhomogeneity at the inhomogeneity level, the block location was an influential factor. For the holes with dimensions of $1 \mathrm{~mm}$ and $3 \mathrm{~mm}$, the correlation across the diagram was not appropriate for running a predictive analysis.

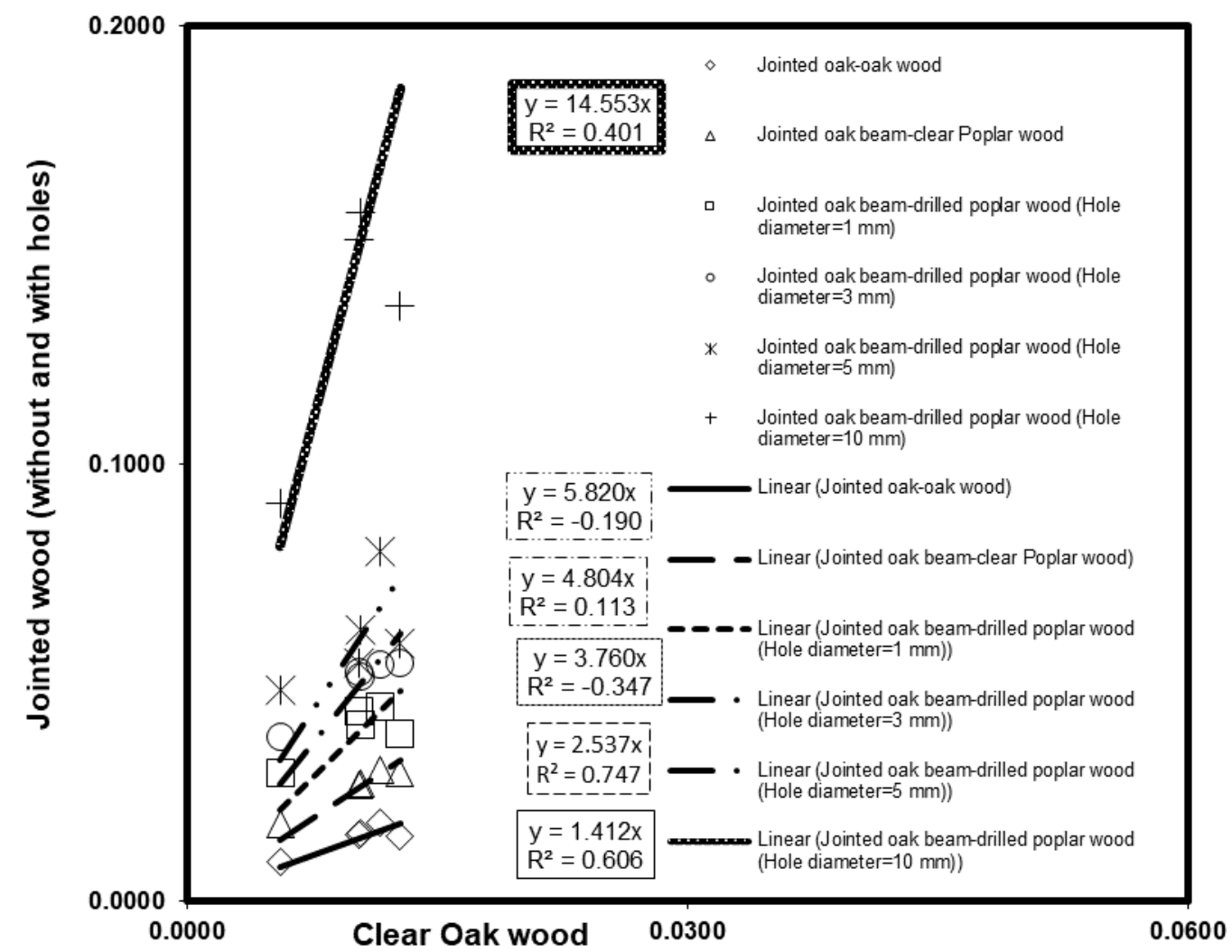

Fig. 10. Comparison of the damping capacity values between clear oak wood and jointed oak wood and poplar block wood without hole before and after, for four drilling stages at the center of the beam (see Fig. 2)

The ACE values decreased in two group joints, as shown in Figs. 11 and 12 at the 95\% confidence level. This factor for the end block augmentation (Fig. 11) was compared with those of the same at the central part, Fig. 12. The ACE applied for the selection of wood in musical instruments is an essential factor (Tsoumis 1991) and is considered to be one of the best factors in discovering the inhomogeneity and its location, even in the areas out of the nodes of the first mode of free flexural vibration in free-free beam. 
The ACE is a major factor in wood, consisting of dynamic moduli of elasticity, density, and damping capacity as the coefficient and final factor for identifying the flawlessness of wood (Kohantorabi et al. 2015). In this study, similar to the process used by Kohantorabi et al. (2015), during the process of discovering inhomogeneity in dried woodworks through different wood drying programs, it was found that the samples with more defects were of lower ACE, with the exception that there, the effect of the location of defect and inhomogeneity was not identifiable, while here it was identifiable through appropriate correlations according to the obtained results and the vibration node and antinode locations (Fig. 6).

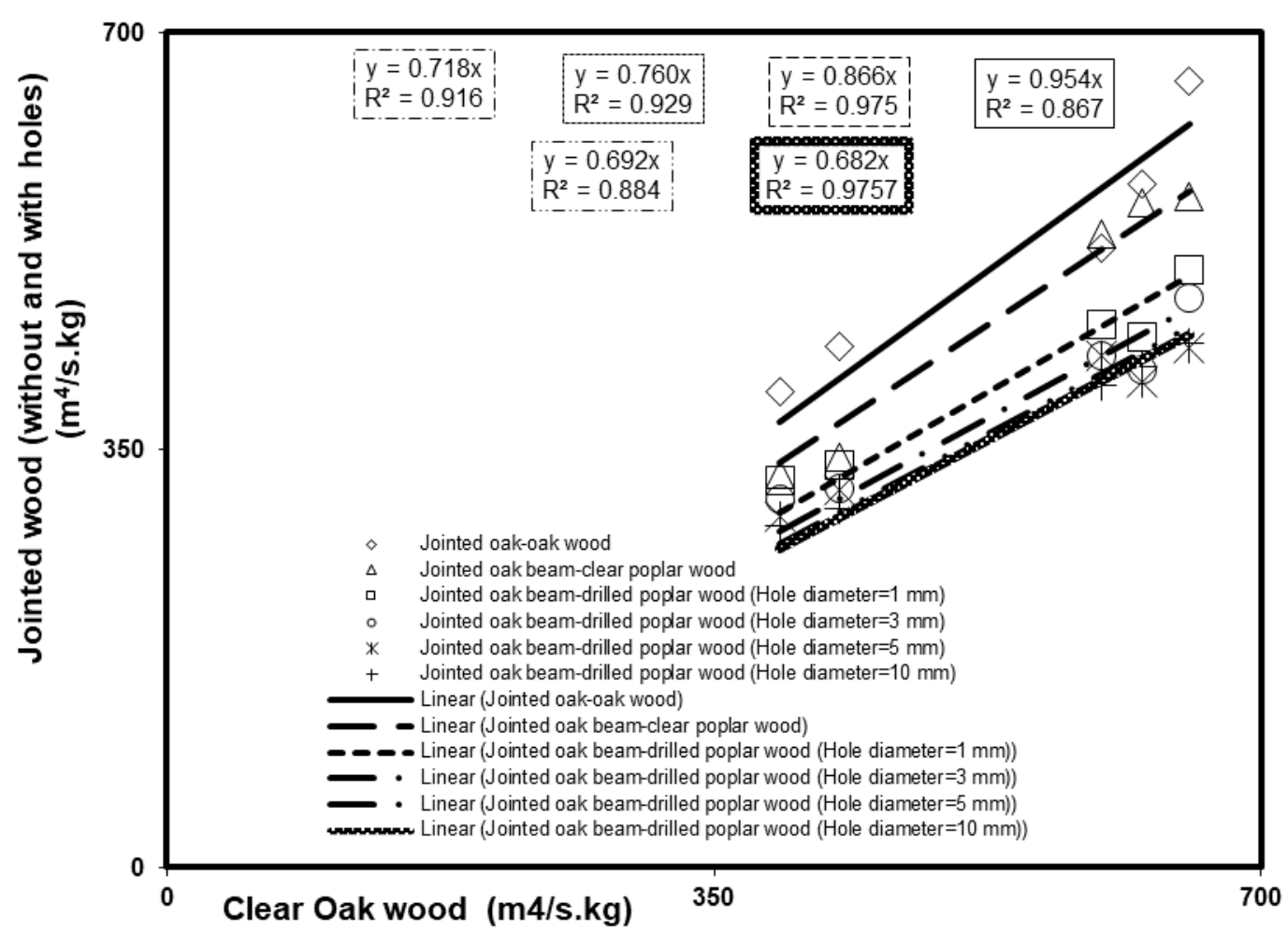

Fig. 11. Comparison of the acoustical conversion efficiency values between clear oak wood and jointed oak wood and poplar block wood without hole before and after, for four drilling stages at one of the ends of the beam (see Fig. 2) 


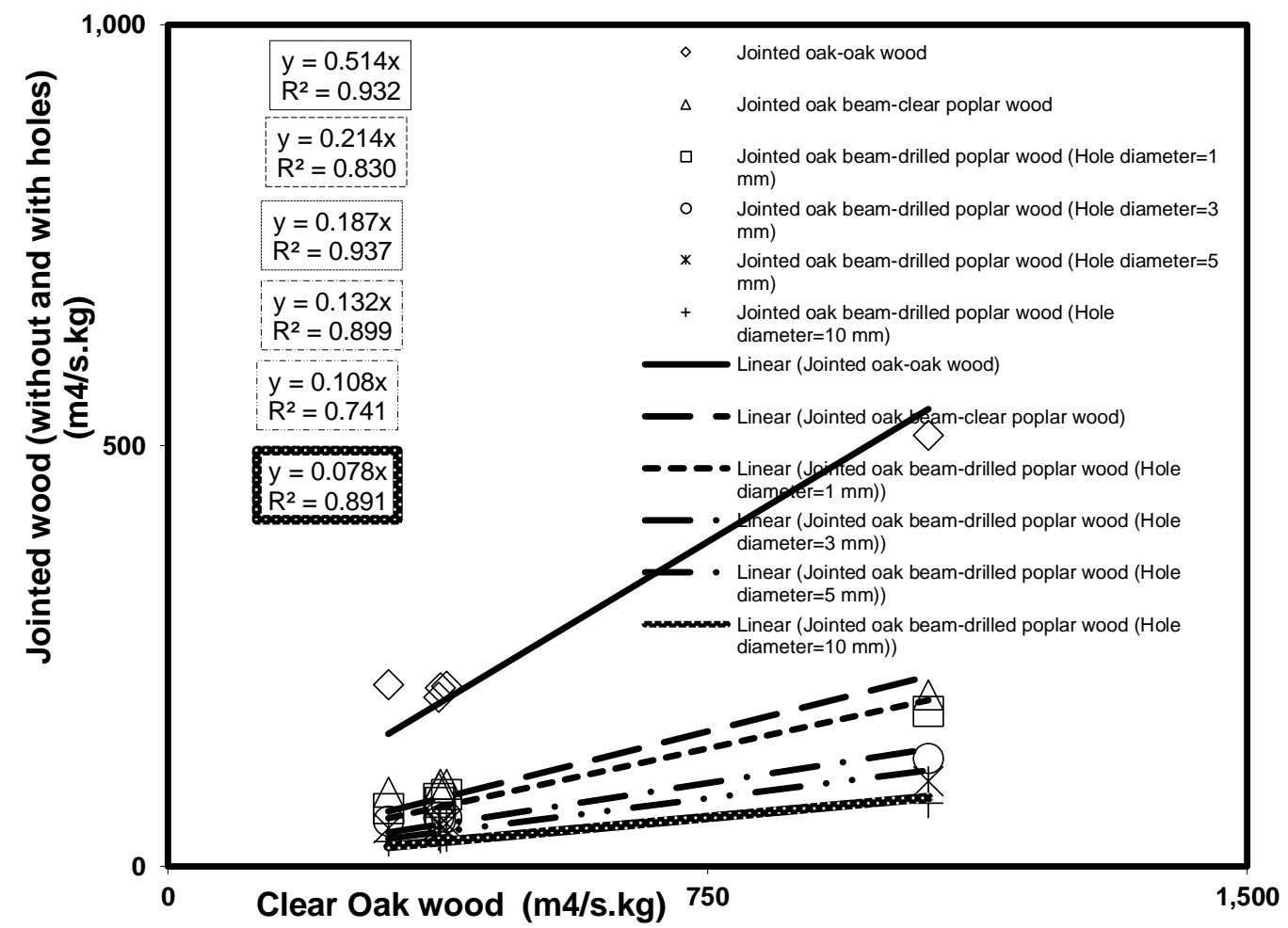

Fig. 12. Comparison of the acoustical conversion efficiency values between clear oak wood and jointed oak wood and poplar block wood without hole before and after, for four drilling stages at the center of the beam (see Fig. 2)

\section{CONCLUSIONS}

1. Inhomogeneity of density at the end of the beam had no effect on the dynamic modulus of elasticity at $95 \%$ confidence level. A minor dynamic response can be observed for the beam vibration only with a $10-\mathrm{mm}$ hole. The same phenomenon in the central part of the beam reduced the frequency of the first mode of vibration, and drilling at any step led to a gradual reduction in value. This was due to the location difference in inhomogeneity of density in relation to the node and antinode vibration for the first mode. In general, this option cannot be appropriate for location finding and types of augmentations and joints.

2. The acoustic coefficient increased based on its correlation with the made joint, though there was a partial decrease in density over the joints of the two groups at at $95 \%$ confidence level. The primary decrease in the acoustic coefficient in the joints made at the central part of the beam was due to a decrease in the dynamic modulus of elasticity value, which increased after drilling. This, as well, cannot be an appropriate factor for identifying the location and the level of density between two inhomogeneity groups.

3. The values of damping capacity in both groups of joints and the density inhomogeneity increased at a higher gradient in the inhomogeneous beam over the central part of the beam in a noticeable manner. This was due to the difference in 
location position from the made density inhomogeneity in relation to the vibration node and the first mode of antinode of free flexural vibration in free-free beam. Because the level of increase in damping capacity values corresponded to the made density inhomogeneity level and drilling, it can be deduced that this factor was relatively appropriate for identifying the location and level of density inhomogeneity.

4. Artificial density inhomogeneity at the end part of the beam and drilling stages did not result in any change in the lengths of the test samples or cause a considerable low changing in density. It did not have an effect on frequency values, but highly influenced on the amplitude.

5. The ACE is one of the parameters for selecting the appropriate wood for use in sound resonators. Greater values of this factor correspond to a higher quality for application in these kinds of performances. However, it seems that the artificial change of density at two locations may not seem sufficient, but in fact, according to the selected locations and the results showed that compared to selecting the node and antinode vibration in two location have most effects with appropriate correlation coefficients. Therefore, it is most suitable for evaluation of the reliable results for predicting the location and the level of defects based on this factor.

\section{ACKNOWLEDGMENTS}

This article is derived from a doctoral thesis by "Mostafa Kohantorabi" (Ph.D. Student of Islamic Azad University, Science and Research Branch - Tehran, Iran) entitled, "Effects of artificial inhomogeneity of density on the dynamic properties of the oak wood (Quercus castaneifolia)". The authors appreciate the support received from the Islamic Azad University, Science and Research Branch-Tehran, Iran. The authors are also thankful for the support from Darkoob Nondestructive Testers, a knowledge-based company at the Islamic Azad University, Karaj Branch-Karaj, Iran, for providing and sharing the NDT$\mathrm{lab}^{\circledR}$ Portable System Setup.

\section{REFERENCES CITED}

Aramaki, M., Bailléres, H., Brancheriau, L., Kronland-Martinet, R., and Ystad, S. (2007). "Sound quality assessment of wood for xylophone bars," Journal of Acoustical Society of America 121(4), 2407-2420. DOI: 10.1121/1.2697154

Ayarkwa, J., Hirashima, Y., and Sasaki, Y. (2001), "Predicting modulus of rupture of solid and finger jointed tropical African hardwoods using longitudinal vibration," Forest Products Journal 51(1), 85-92.

Bodig, J., and Jayne, B. A. (1993). Mechanics of Wood and Wood Composites (Persian Translation by Ebrahimi G.), University of Tehran Press, Tehran, Iran.

Bordonné, P. A. (1989). Dynamic Modulus and Internal Friction of Wood: Measurements in Natural Vibrations of Both Ends Free Beams, Ph.D. Dissertation, INP de Lorraine, Nancy, France. 154pp. 
Brancheriau, L., and Bailleres, H. (2002). "Natural vibration analysis of clear wooden beams: A theoretical review," Wood Science and Technology 36(4), 347-365. DOI: 10.1007/s00226-002-0143-7

Brancheriau, L., Kouchade, C., and Bremaud, I. (2010). "Internal friction measurement of tropical species by various acoustic methods," Journal of Wood Science 56(5), 371379. DOI: $10.1007 / \mathrm{s} 10086-010-1111-8$

Bucur, V. (2006). Acoustics of Wood, $2^{\text {nd }}$ Ed., Springer-Verlag Berlin, Germany.

Harris, C. M., and Piersol, A. G. (2002). Harris' Shock and Vibration Handbook, McGraw-Hill, New York, NY, USA.

$\mathrm{Hu}$, C. S., and Afzal, M. T. (2006). "A wavelet analysis-based approach for damage localization in wood beams," Journal of Wood Science 52(5), 456-460. DOI: 10.1007/s10086-005-0783-y

Hu, Y., Nakao, T., Nakai, J., and Gu, F. (2005). "Dynamic properties of three types of wood-based composites," J. Wood Sci. 51, 7-12. DOI: 10.1007/s10086-003-0614-y

ISO 3129 (1975). "Wood - Sampling methods and general requirements for physical and mechanical testing of small clear wood specimens," International Organization for Standardization, Geneva, Switzerland.

Kohantorabi, M., Hossein, M. A., Shahverdi, M., and Roohnia, M. (2015). "Vibration based NDT methods to verify wood drying efficiency," Drvna Industrija 66(3), 221228. DOI: $10.5552 /$ drind.2015.1352

Kubojima, Y., Tonosaki, M., and Yoshihara, H. (2005). "Effect of additional mass on the Young's Modulus of a wooden beam," Journal of Testing and Evaluation 33(4), 278282. DOI: $10.1520 / J T E 11937$

Kubojima, Y., Suzuki, Y., and Tonosaki, M. (2014). "Effect of additional mass on the apparent Young's Modulus of a wooden bar by longitudinal vibration," BioResources 9(3), 5088-5098. DOI: 10.15376/biores.9.3.5088-5098

Nzokou, P., Freed, J., and Kamden, D. P. (2006). "Relationship between nondestructive and static modulus of elasticity of commercial wood plastic composites," Hols als Roh und Werkstoff 64(2), 90-93. DOI: 10.1007/s00107-005-0080-x

Ono, T., and Norimoto, M. (1983). "Study on Young's modulus and internal friction of wood in relation to the evaluation of wood for musical instruments," Japanese Journal of Applied Physics 22(4), 611-614. DOI: 10.1143/JJAP.22.611

Ouis, D. (2004). "Assessment of severity and localization of a transversal crack in a wood beam through a study of its natural modes of vibration," Holz als Roh und Werkstoff 62, 17-22. DOI: 10.1007/s00107-003-0442-1

Roohnia, M. (2007). "NDT-LAB; System to evaluate the mechanical properties of wood," Iranian Patent No. 44032/22-08-1386.

Roohnia, M., Yavari, A. and Tajdini, A. (2010). "Elastic parameters of poplar wood with end-cracks," Annals of Forest Science 67(4), 1-6. DOI: 10.1051/forest/2009129

Roohnia, M., Alavi-Tabar, S. E., Hossein, M. A., Brancheriau, L., and Tajdini, A. (2011). "Dynamic modulus of elasticity of drilled wooden beams," Nondestructive Testing and Evaluation 26(2), 141-153. DOI: 10.1080/10589759.2010.533175

Roohnia, M., Kohantorabi, M., Jahan-Latibari, A., Tajdini, A., and Ghaznavi, M. (2012). "Nondestructive assessment of glued joints in timber applying vibration-based methods," European Journal of Wood and Wood Products 70(6), 791-799. DOI: 10.1007/s00107-012-0616-9 
Roohnia, M., and Kohantorabi, M. (2015). "Dynamic methods to evaluate the shear modulus of wood." BioResources 10(3), 4867-4876. DOI: 10.15376/biores.10.3.4867-4876

Roohnia, M. (2019). "Wood: Vibration and acoustic properties," in: Reference Module in Materials Science and Materials Engineering, $19^{\text {th }}$ Ed., Elsevier Inc., Amsterdam, Netherlands, Available online. DOI: 10.1016/B978-0-12-803581-8.01996-2

Sedik, Y., Hamdan, S., Jusoh, I., and Hasan, M. (2010). "Acoustic properties of selected tropical wood species," Journal of Nondestructive Evaluation 29(1), 38-42. DOI 10.1007/s10921-010-0063-7

Timoshenko, S. P. (1921). "On the correction for shear of the differential equation for transverse vibrations of prismatic bars," The London, Edinburgh, and Dublin Philosophical Magazine and Journal of Science 41(6), 744-746. DOI: 10.1080/14786442108636264.

Tsoumis, G. (1991). Science and Technology of Wood, Van Nostrand Reinold, 204-207. Wang, S., Chen, J., Tsai, M., Lin, C., Yang, T. (2008). "Grading of Softwood Lumber Using Non-destructive Techniques.” Journal of Material Processing Technology 208 (1): 149-158. DOI: 10.1016/j.jmatprotec.2007.12.105.

Yang, T. H., Wang, S. Y., Lin C. J., and Tsai, M. J. (2008). "Evaluation of the mechanical properties of Douglas-fir and Japanese cedar lumber and its structural glulam by nondestructive techniques," Construction and Building Materials 22(4), 487-493. DOI: 10.1016/j.conbuildmat.2006.11.012

Article submitted: Dec. 29, 2019; Peer review completed: April 25, 2020; Revised version received and accepted: April 26, 2020; Published: May 5, 2020.

DOI: 10.15376/biores.15.3.4711-4726 